\title{
Thrap3 docks on phosphoserine 273 of PPAR $\gamma$ and controls diabetic gene programming
}

\author{
Jang Hyun Choi, ${ }^{1}$ Sun-Sil Choi, ${ }^{1}$ Eun Sun Kim, ${ }^{1}$ Mark P. Jedrychowski, ${ }^{2}$ Yong Ryoul Yang, ${ }^{1}$ \\ Hyun-Jun Jang, ${ }^{1}$ Pann-Ghill Suh, ${ }^{1}$ Alexander S. Banks, ${ }^{3}$ Steven P. Gygi, ${ }^{2}$ and Bruce M. Spiegelman ${ }^{4}$ \\ ${ }^{1}$ Department of Biological Sciences, Ulsan National Institute of Science and Technology (UNIST), Ulsan 689-798, Korea; \\ ${ }^{2}$ Department of Cell Biology, Harvard Medical School, Boston, Massachusetts 02115, USA; ${ }^{3}$ Division of Endocrinology, Diabetes, \\ and Hypertension, Brigham and Women's Hospital, Harvard Medical School, Boston, Massachusetts 02115, USA; ${ }^{4}$ Department \\ of Cancer Biology, Dana-Farber Cancer Institute, Harvard Medical School, Boston, Massachusetts 02115, USA
}

\begin{abstract}
Phosphorylation of peroxisome proliferator-activated receptor $\gamma(\operatorname{PPAR} \gamma)$ at Ser273 by cyclin-dependent kinase 5 (CDK5) in adipose tissue stimulates insulin resistance, but the underlying molecular mechanisms are unclear. We show here that Thrap3 (thyroid hormone receptor-associated protein 3) can directly interact with PPAR $\gamma$ when it is phosphorylated at Ser273, and this interaction controls the diabetic gene programming mediated by the phosphorylation of PPAR $\gamma$. Knockdown of Thrap3 restores most of the genes dysregulated by CDK5 action on PPAR $\gamma$ in cultured adipocytes. Importantly, reduced expression of Thrap3 in fat tissue by antisense oligonucleotides (ASOs) regulates a specific set of genes, including the key adipokines adiponectin and adipsin, and effectively improves hyperglycemia and insulin resistance in high-fat-fed mice without affecting body weight. These data indicate that Thrap3 plays a crucial role in controlling diabetic gene programming and may provide opportunities for the development of new therapeutics for obesity and type 2 diabetes.
\end{abstract}

[Keywords: PPAR $\gamma$; phosphorylation; Thrap3 interaction; gene reprogramming; energy homeostasis]

Supplemental material is available for this article.

Received July 21, 2014; revised version accepted September 26, 2014.

Over the last 20 years, adipose tissue has emerged as a central regulator of energy homeostasis and metabolic disorders. Obesity develops when energy intake exceeds energy expenditure (Mokdad et al. 2001; Bray and Bellanger 2006; Rosen and Spiegelman 2014). Excessive energy intake in our body leads to increased adipose mass, ectopic lipid deposition, insulin resistance, type 2 diabetes, cardiovascular diseases, and certain cancers (Calle et al. 2003; Van Gaal et al. 2006; Hsu et al. 2007). The contribution of lipid overload and lipotoxicity in perturbing insulin signaling pathways has been highlighted (Unger 2002), as has the proinflammatory signaling arising in the adipose tissues of obese animals (Hotamisligil et al. 1993; Kershaw and Flier 2004; Lagathu et al. 2006). Thus, understanding the molecular mechanisms of glucose and lipid homeostasis in adipose tissue is crucial for the prevention and treatment of type 2 diabetes and other comorbidities of obesity.

Peroxisome proliferator-activated receptor $\gamma(\operatorname{PPAR} \gamma)$ is a member of the nuclear receptor superfamily of

Corresponding authors: bruce_spiegelman@dfci.harvard.edu,janghchoi@ unist.ac.kr

Article published online ahead of print. Article and publication date are online at http://www.genesdev.org/cgi/doi/10.1101/gad.249367.114. ligand-activated transcription factors (Tontonoz et al. 1994; Willson et al. 2001). It is highly expressed in adipose tissue and regulates diverse biological functions, including adipocyte differentiation, lipid and glucose metabolism, and inflammation (Tontonoz and Spiegelman 2008). While the identity of biologically significant endogenous activators of PPAR $\gamma$ has remained a mystery, the anti-diabetic thiazolidinedione (TZD) class of anti-diabetic drugs, which includes rosiglitazone and pioglitazone, are full agonist ligands for PPAR $\gamma$ (Lehmann et al. 1995). PPAR $\gamma$ binds as a heterodimer with retinoid $\mathrm{X}$ receptor (RXR) to DNA repeats of the sequence AGGTCA, separated by a single nucleotide (DR1 elements), and the PPAR $\gamma /$ RXR heterodimer can control thousands of target genes in different cells (Kliewer et al. 1992; Mangelsdorf and Evans 1995; Chandra et al. 1998). The transcriptional activity of PPAR $\gamma$ is regulated by interactions with several cofactors. In the absence of ligands, PPAR $\gamma$ preferentially interacts with

(c) 2014 Choi et al. This article is distributed exclusively by Cold Spring Harbor Laboratory Press for the first six months after the full-issue publication date (see http://genesdev.cshlp.org/site/misc/terms.xhtml). After six months, it is available under a Creative Commons License (Attribution-NonCommercial 4.0 International), as described at http:// creativecommons.org/licenses/by-nc/4.0/. 
nuclear receptor corepressor 1 (NCOR1) and silencing mediator for retinoid and thyroid receptor (SMRT/ NCOR2). These platforms recruit chromatin-modifying enzymes such as histone deacetylases to repress transcription (Chen and Evans 1995; Hörlein et al. 1995). Conversely, in the presence of agonist ligands, PPAR $\gamma$ interacts with coactivators such as steroid receptor coactivators (SRCs), PPAR $\gamma$ coactivator 1s (PGC1s), histone acetyltransferases (HATs), and the Mediator complex, all of which promote gene transcription (Fondell et al. 1996; DiRenzo et al. 1997; Nolte et al. 1998; Puigserver et al. 1998; Ge et al. 2002).

Recently, we found that PPAR $\gamma$ was phosphorylated at a specific site, Ser273, by cyclin-dependent kinase 5 (CDK5) in obese and diabetic mice. The phosphorylation of PPAR $\gamma$ at this site did not alter its adipogenic activity but dysregulated a specific set of genes whose expression was altered in obesity and diabetes (Choi et al. 2010, 2011). The underlying mechanism linking PPAR $\gamma$ Ser273 phosphorylation and dysregulation of specific genes is unclear. One possible explanation would be a difference in the ability of phosphorylated PPAR $\gamma$ to be recruited to or bind to DNA. However, comparing the chromatin association of phosphorylated and nonphosphorylated PPAR $\gamma$ (Choi et al. 2010), there were no differences in DNA binding between wild-type and phospho-defective mutant proteins. This suggests that other mechanisms, such as selective coregulator recruitment to PPAR $\gamma$, may be regulated in a phosphorylation-dependent manner.

Here we show that Thrap3 (thyroid hormone receptorassociated protein 3) can preferentially interact with PPAR $\gamma$ when Ser273 is phosphorylated. Knockdown of Thrap3 in mature adipocytes restores most of the genes dysregulated by PPAR $\gamma$ phosphorylation by CDK5 without altering adipogenesis. Reductions in Thrap3 levels in fat tissue with antisense oligonucleotides (ASOs) improve glucose homeostasis in obese mice and stimulate an antidiabetic pattern of gene expression, including increases in the expression of the key adipokines adiponectin and adipsin. These data strongly suggest that Thrap3 plays a critical role of controlling diabetic gene programing and that Thrap3/PPAR $\gamma$ complexes can be a potent therapeutic target for obesity and type 2 diabetes.

\section{Results}

\section{Identification of Thrap3 binding to phosphorylated} PPAR $\gamma$

Previous reports have demonstrated that CDK5-mediated phosphorylation of PPAR $\gamma$ is involved in the pathogenesis of insulin resistance through dysregulation of a specific set of genes. However, the mechanism driving this effect is unclear. There were no differences in DNA binding between wild-type PPAR $\gamma$ and phosphorylation-defective mutant proteins (PPAR $\gamma$ S273A), suggesting that coregulators were differentially recruited to PPAR $\gamma$ and transcriptionally regulated genes in a phosphorylation-dependent manner (Choi et al. 2010). We therefore performed proteomic analyses of binding complexes formed with wild-type
PPAR $\gamma$ or the PPAR $\gamma$ S273A mutant allele in the absence or presence of TNF- $\alpha$, a cytokine that activates CDK5. Binding partners that copurified preferentially with wildtype PPAR $\gamma$ in the presence of TNF- $\alpha$ were thus identified. As shown in Figure 1A, several bands of potential interest were observed and subjected to liquid chromatography combined with tandem mass spectrometry (LC-MS/MS). Thrap3 specifically interacted with wild-type PPAR $\gamma$ following TNF- $\alpha$ treatment but was not observed in association with PPAR $\gamma$ S273A in cells treated with TNF- $\alpha$. Thrap3 is known to be a coregulatory protein that is loosely associated with the Mediator complex (Fondell et al. 1996; Ito et al. 2002) and is also reported to regulate several transcription factors (Lande-Diner et al. 2013). Thrap3 is therefore a plausible candidate for involvement in phosphorylation-mediated PPAR $\gamma$ regulation.

To confirm and extend our understanding of this interaction, we immunoprecipitated endogenous PPAR $\gamma$ from TNF- $\alpha$ cultured adipocytes and detected endogenous Thrap3 by Western blotting (Fig. 1B). As shown in Figure 1B, PPAR $\gamma$ was phosphorylated by treatment with TNF- $\alpha$, and the interaction between PPAR $\gamma$ and Thrap3 was detected only when PPAR $\gamma$ was phosphorylated at Ser273. In addition, when wild-type PPAR $\gamma$ and PPAR $\gamma$ S273A were expressed in parallel with CDK5/p35 in cells, PPAR $\gamma$ S273A failed to interact with Thrap3 (Fig. 1C). Consistent with previous studies, rosiglitazone (PPAR $\gamma$ full agonist ligand), MRL24 (PPAR $\gamma$ partial agonist ligand), and SR1664 (nonagonist PPAR $\gamma$ ligand) significantly suppressed PPAR $\gamma$ phosphorylation after TNF- $\alpha$ treatment in adipocytes (Choi et al. 2011). Importantly, the interaction between PPAR $\gamma$ and Thrap3 was also reduced after ligand treatments (Fig. 1D). All of these data strongly suggest that Thrap3 may be a binding partner of PPAR $\gamma$, specifically when it is phosphorylated at Ser273.

\section{Thrap3 interacts directly with PPAR $\gamma$ phosphorylated} at Ser273

Next, we performed a reconstitution experiment to test whether PPAR $\gamma$ binds to Thrap3 directly. Wild-type PPAR $\gamma$ and PPAR $\gamma$ S273A were purified from cells and then incubated with the active CDK5/p35 kinase complex using an in vitro kinase assay that we previously reported (Choi et al. 2010). The mixture was then further incubated with immunopurified Thrap3 protein. As shown in Figure 2A, wild-type PPAR $\gamma$, but not PPAR $\gamma$ S273A, was phosphorylated by CDK5/p35 and interacted with Thrap3. We next synthesized biotin-conjugated peptides containing a phosphorylated Ser273 (phosphopeptide) residue or a nonphosphorylated Ser273 (nonphosphopeptide) and tested Thrap3 interaction with these peptides. As shown in Figure 2B, the phosphorylated peptide interacted with Thrap3, but the nonphosphorylated peptide did not.

The specific amino acid requirements for Thrap3's interaction with PPAR $\gamma$ were further investigated using recombinant Thrap3 fragments (Supplemental Fig. S1A). As shown in Supplemental Figure S1B, we found that 


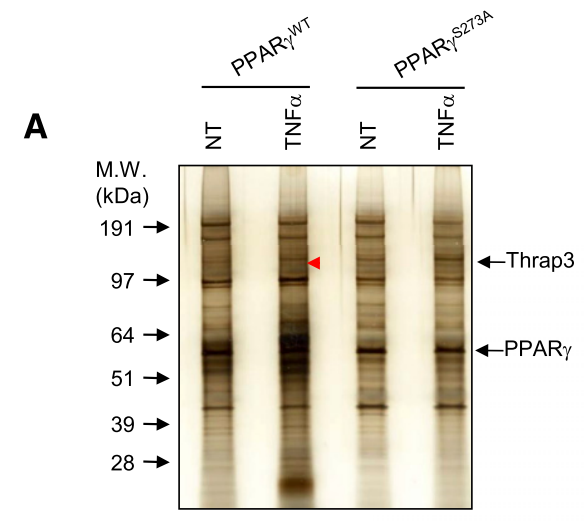

B
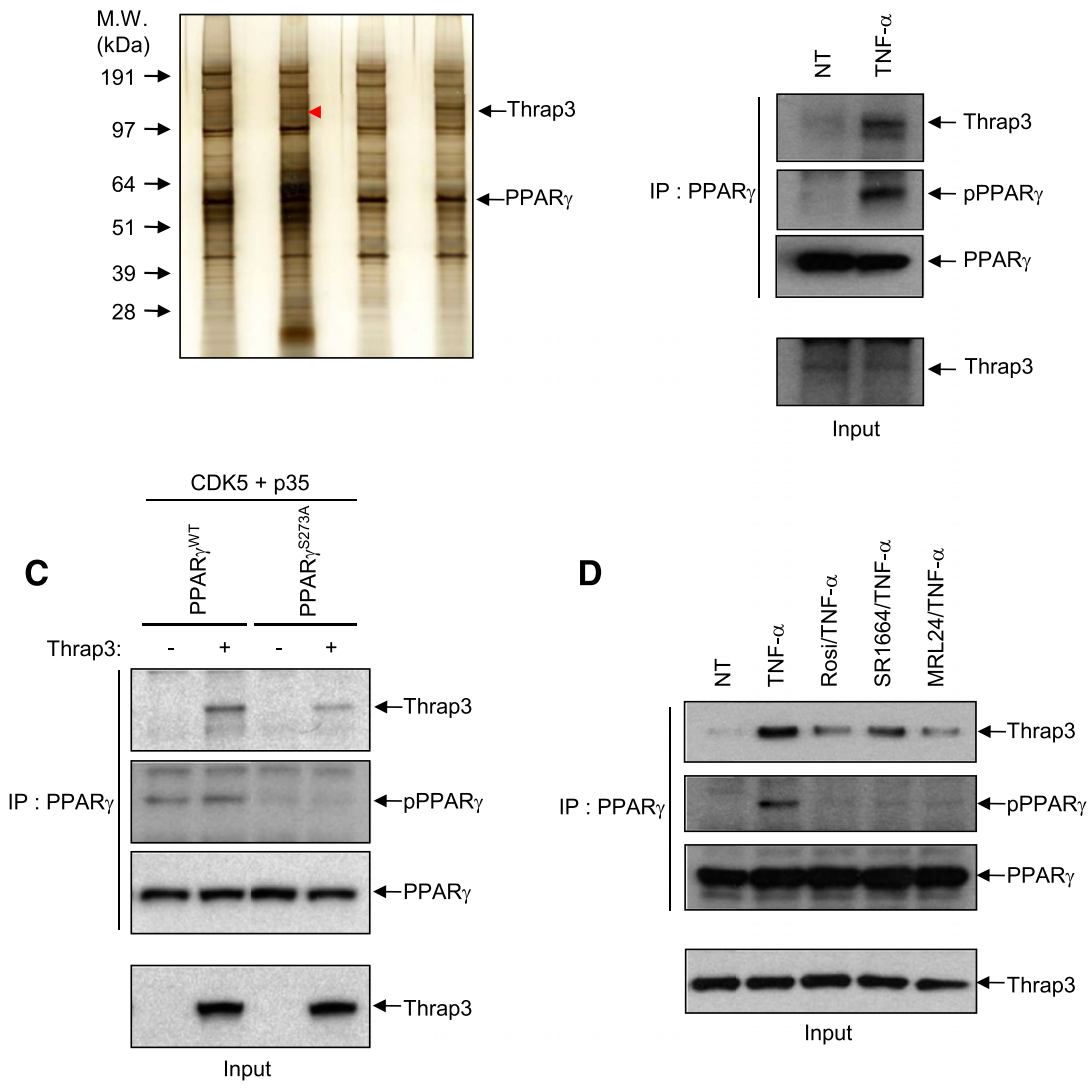

Figure 1. Identification of a critical binding partner to phosphorylated PPAR $\gamma$. (A) Silver staining of the PPAR $\gamma$ and its associated proteins. Wild-type (WT) or S273A PPAR $\gamma$ complexes, as labeled, were purified using Flag M2 agarose. (B) The PPAR $\gamma$ complexes were immunopurified from adipocytes, and endogenous Thrap3 was detected by Western blotting. $(C)$ CDK5/p35 and PPAR $\gamma$ were expressed in HEK-293 cells, cell lysates were incubated with Flag M2 agarose, and Thrap3 binding was analyzed with Thrap3 antibody. $(D)$ Interaction between Thrap3 and phosphorylated PPAR $\gamma$ was analyzed after treatment with rosiglitazone, MRL24, or SR1664. deleting the $\mathrm{C}$ terminus region (amino acids 597-955) of Thrap3 abrogated the PPAR $\gamma$ interaction in cells. The specific binding region of Thrap3 interacting with PPAR $\gamma$ was further dissected. As shown in Figure 2, C and D, the amino acid 640-680 region of Thrap3 specifically bound to PPAR $\gamma$. In addition, a GST fragment of Thrap3 (amino acids 640-680) interacted with phosphorylated wild-type PPAR $\gamma$, and the PPAR $\gamma$ S273A mutant did not interact with Thrap3 fragments. Taken together, these results strongly suggest that Thrap3 directly interacts with phosphorylated PPAR $\gamma$ at Ser273.

Thrap3 specifically controls a diabetic gene set in cultured adipocytes and insulin sensitivity in vivo

To examine the functional role of the interaction between Thrap3 and PPAR $\gamma$ in adipocytes, we examined gene expression in cells with reduced expression of Thrap3. Lentivirus expressing a short hairpin scrambled control RNA (Scr shRNA) or shRNAs targeting Thrap3 were transduced into fully differentiated adipocytes. As shown in Figure 3, B and C, knockdown of Thrap3 dramatically reduced mRNA and protein expression of Thrap3 in adipocytes but did not alter the capability of adipocyte differentiation, as confirmed by Oil-Red-O staining (Fig. 3A). While classical adipocyte-selective genes like aP2 were expressed to equal levels between the Scr
shRNA-expressing and Thrap3 shRNA-expressing adipocytes, most of the genes known to be specifically dysregulated by CDK5-mediated phosphorylation of PPAR $\gamma$ were sensitive to knockdown of Thrap3. These include adiponectin and adipsin, key adipokine regulators of insulin sensitivity and glucose homeostasis (Fig. 3C).

In previous reports, we showed that CDK5-mediated phosphorylation of PPAR $\gamma$ could promote insulin resistance (Choi et al. 2010; Li et al. 2011). To explore the role of Thrap3 in glucose metabolism in vivo, we used a specific ASO to suppress the expression of Thrap3. Previous reports have shown that ASO treatment can lead to repression of specific gene expression in several tissues in vivo, particularly liver and adipose tissue (Supplemental Figs. S2, S3; Watts et al. 2005; Kumashiro et al. 2013). Thus, we synthesized and tested specific ASOs against Thrap3 that contains the same sequence as the shRNA used in Figure 3. The Thrap3 ASO was first tested in lean mice fed normal chow (Supplemental Fig. S2). Mice were treated with control or Thrap3 ASO at a dose of $20 \mathrm{mg} / \mathrm{kg}$ twice a week for $3 \mathrm{wk}$. ASO treatment resulted in a reduction of Thrap3 protein expression in fat tissue (Supplemental Fig. S2A). Interestingly, Thrap3 ASO treatment improved glucose tolerance in mice without affecting body weight (Supplemental Fig. S2B-D). We then performed a critical experiment, assessing whether Thrap3 ASO can 
Choi et al.

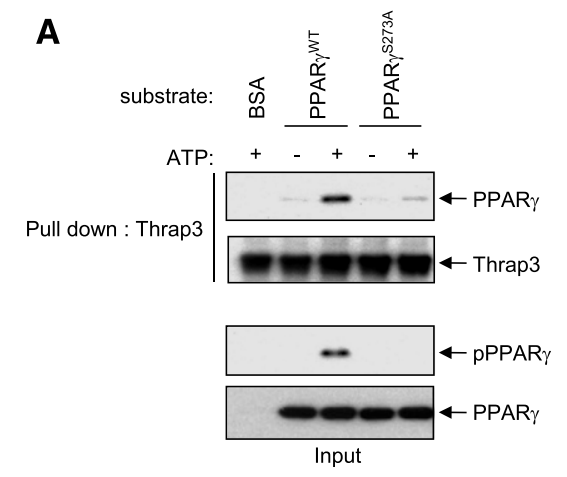

C
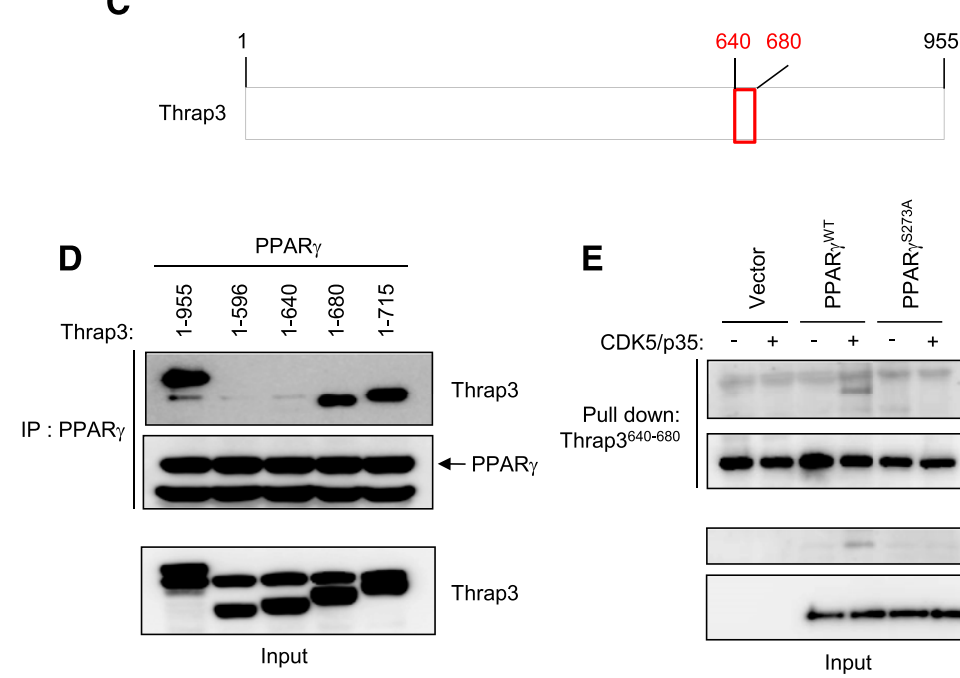

B

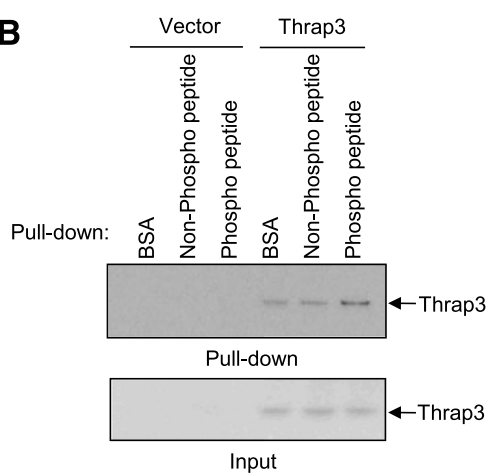

955

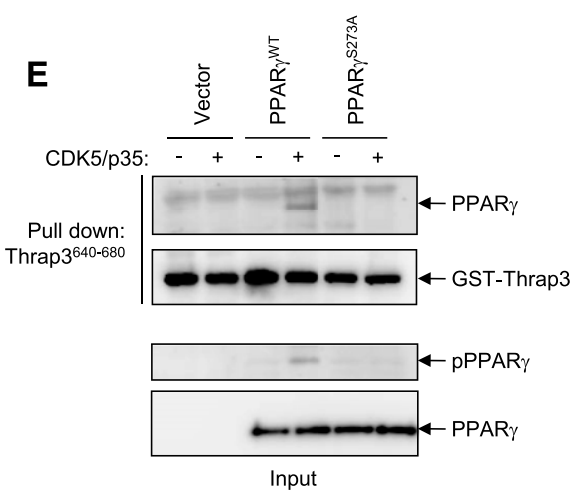

Figure 2. Thrap3 directly interacts with phosphorylated PPAR $\gamma$. (A) An in vitro protein kinase assay was performed using CDK5/p35 with either wild-type (WT) PPAR $\gamma$ or PPAR $\gamma$ S273A. These mixtures were further incubated with immunopurified Thrap3, and the interaction between Thrap3 and PPAR $y$ was analyzed with a Thrap3 antibody. (B) Biotin-conjugated peptides flanking phosphorylated or nonphosphorylated Ser273 were incubated with Thrap3-expressing cell lysates and purified peptide-bound complexes using avidin-Sepharose. Thrap3 was detected from these complexes by Western blotting. $(C)$ Schematic illustration of the binding region of Thrap3. (D) Several HA-tagged deletion mutants of Thrap3 were generated and were expressed with PPAR $\gamma$ in HEK-293 cells. From the PPAR $y$ complexes, Thrap 3 was analyzed with anti-HA antibody. (E) A GSTfused fragment of Thrap3 (amino acids 640680) was incubated with CDK5/p35- and PPAR $\gamma$-expressing cell lysates, and phosphorylation of PPAR $\gamma$ was analyzed with phospho-specific PPAR $\gamma$ antibody against phosphoserine 273. Thrap3 complexes were isolated by using GSH Sepharose and analyzed with anti-PPAR $\gamma$ antibody. improve glucose homeostasis and insulin sensitivity in mice with diet-induced obesity. As shown in Figure 4A, Thrap3 ASO treatment at $40 \mathrm{mg} / \mathrm{kg}$ for $3 \mathrm{wk}$ resulted in an $\sim 50 \%$ reduction of Thrap3 protein expression in white adipose tissue compared with controls. In addition, treatment with Thrap3 ASO dramatically improved glucose tolerance and insulin sensitivity in high-fat-fed mice, as determined by glucose and insulin tolerance tests (Fig. 4B, C); both fasting glucose and fasting insulin levels were reduced without affecting body weight (Fig. 4D-F). Insulin resistance, as computed by homeostasis model assessment of insulin resistance (HOMA-IR), showed a clear improvement with Thrap3 ASO treatment (Fig. 4G). Furthermore, Thrap3 ASO treatment decreased serum triacylglycerol (TG) as well as cholesterol levels compared with control ASO-treated mice (Fig. 4H,I). These data strongly suggest that Thrap3 can play a key role in regulating insulin sensitivity in vivo.

We also asked whether Thrap3 controls diabetic gene programming in vivo. As shown in Figure 5A, treatment with Thrap3 ASO in high-fat-fed mice caused changes in the expression of nine out of 17 of the diabetic genes that are significantly controlled by CDK5 action on PPAR $\gamma$ (Choi et al. 2010). For example, adiponectin and adipsin are genes whose expression is recognized as being reduced in obesity and diabetes (Flier et al. 1987; Hu et al. 1996; Trujillo and Scherer 2006); both are induced by Thrap3
ASO treatment. Consistent with previous data (Fig. 3C), $C d 24 a, D d x 17, N r 3 c 1$, and Rybp were also induced by the treatment of Thrap3 ASO. In addition, the mRNA and serum levels of adiponectin were increased by the treatment of Thrap3 ASO (Fig. 5B). Furthermore, Thrap3 ASO treatment dramatically increased adipsin levels in serum, consistent with mRNA induction (Fig. 5C). These data strongly suggest that Thrap3 plays a key role in regulating gene expression associated with PPAR $\gamma$ phosphorylation at Ser273.

\section{Discussion}

Previous reports strongly suggested that obesity-linked phosphorylation of PPAR $\gamma$ by CDK5 is causally related to the development of insulin resistance through dysregulated expression of a specific subset of PPAR $\gamma$ target genes (Choi et al. 2010, 2011). A crucial question then is how this phosphorylation of PPAR $\gamma$ at Ser273 functions at a mechanistic level. Using biochemical and proteomic methods, we identified Thrap3 as a key coregulatory protein that interacts directly with $\operatorname{PPAR} \gamma$, specifically when it is phosphorylated at Ser273. Importantly, loss of Thrap3 expression in cells does not alter adipogenesis but restores expression of the subset of genes that are dysregulated by CDK5-mediated phosphorylation of PPAR $\gamma$. Finally, knockdown of Thrap3 through the use of an 
A

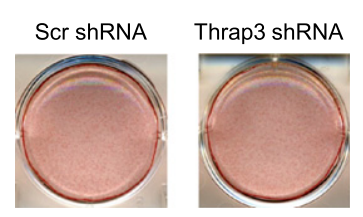

C

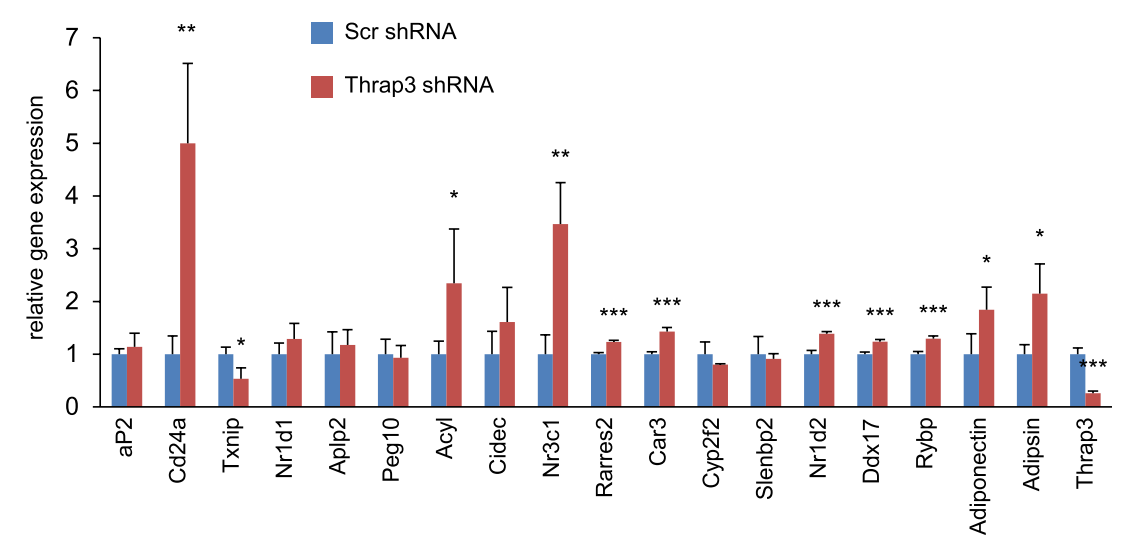

B

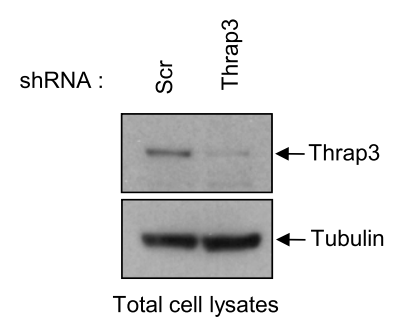

Figure 3. Thrap3 specifically controls a diabetic gene set in cultured adipocytes. $(A)$ 3T3-L1 cells expressing Scr or Thrap3 shRNA were stained with Oil-Red-O $7 \mathrm{~d}$ after adipocyte differentiation. $(B)$ Expression of Thrap3 protein was analyzed with anti-Thrap3 antibody. $(C)$ Specific genes that are dysregulated by CDK5/PPAR $\gamma$ phosphorylation expression were analyzed by real-time quantitative PCR (qPCR) $(n=3)$. Error bars are SEM. $\left(^{\star}\right) P<0.05$; $\left(^{\star \star}\right) P<0.01 ;\left(^{\star \star \star}\right) P<0.001$.

ASO controls diabetic gene programming in fat tissue and dramatically improves insulin resistance (Fig. 5D).

While the potential pathogenic roles for many genes dysregulated by CDK5/PPAR $\gamma$ phosphorylation are unknown, Thrap3 appears to act as a suppressor of two adipokines with known and important functions in fat tissues: adiponectin and adipsin. Adipsin was the first recognized adipokine (Cook et al. 1987; Flier et al. 1987) and embodies complement factor D activity (Rosen et al. 1989|. Very recent work illustrates that adipsin and the alternative complement cascade that it catalyzes play major roles in the regulation of $\beta$-cell function and insulin secretion (Lo et al. 2014). Adiponectin is a well-studied $\operatorname{PPAR} \gamma$ target and adipokine that exerts insulin-sensitizing and anti-inflammatory actions on many different cell types (Hu et al. 1996; Berg et al. 2001; Yamauchi et al. 2001). Importantly, the role of adiponectin as an endogenous insulin sensitizer has been illustrated in both knockout and transgenic mice (Maeda et al. 2002; Kim et al. 2007). Together, Thrap3 functions in adipose tissue at least partly through the docking on PPAR $\gamma$ in fat cells and appears to be an important component of obesity-linked insulin resistance. It is also worth noting that phosphorylation of PPAR $\gamma$ at Ser273 also increases the interaction between PPAR $\gamma$ and NCOR1, a corepressor protein of nuclear receptors. It is not known whether the NCOR1/PPAR $\gamma$ interaction is direct or Thrap3 is embedded in a complex that includes NCOR (Li et al. 2011).

Thrap3 was originally identified as a protein that interacted with the thyroid receptor in a ligand-dependent manner (Fondell et al. 1996). In this context, it was copurified with the Mediator complex, but further analyses indicated that Thrap3 is not a core component of the
Mediator (Yuan et al. 1998; Fondell et al. 1999; Ito et al. 1999, 2002). Another study showed that Thrap3 could interact with PPAR $\gamma$, and Thrap3 expression was required for adipose differentiation (Katano-Toki et al. 2013). More recent studies have demonstrated that Thrap3 is a selective transcriptional coactivator for CLOCK-BMAL1, a common circadian clock factor, and depletion of Thrap3 causes low-amplitude, long-period circadian rhythms, identifying it as a positive clock element (Lande-Diner et al. 2013). In addition, it has been reported that phosphorylation of PSF/SFPQ by glycogen synthase kinase 3 (GSK3) promotes an interaction with Thrap3 and prevents PSF from binding to the CD45 promoter (Heyd and Lynch 2010). In this model, the crucial regulatory idea is the phosphorylation-dependent interaction of PSF with Thrap3. Together with the data presented here, these data suggest a model in which Thrap 3 could act as a specialized coregulator that docks on certain transcription factors when they are phosphorylated.

The current studies open up further possibilities for anti-diabetic drug development. Our previous work showed that PPAR $\gamma$ ligands could be synthesized to disrupt Ser273 phosphorylation without having any classical agonist activity (Choi et al. 2010). In fact, nonagonist ligands that controlled PPAR $y$ modification at Ser273, like SR1664, were anti-diabetic (Choi et al. 2011). It now seems plausible that assays could be developed to screen for compounds that interfere with the docking of Thrap3 on PPAR $\gamma$. Such compounds might act through the ligand-binding domain (LBD) of PPAR $\gamma$ but might also avoid this LBD pocket to interact with the external faces of either PPAR $y$ or Thrap3. Based on the work presented here, such compounds would be predicted to be anti- 
Choi et al.

$\mathbf{A}$
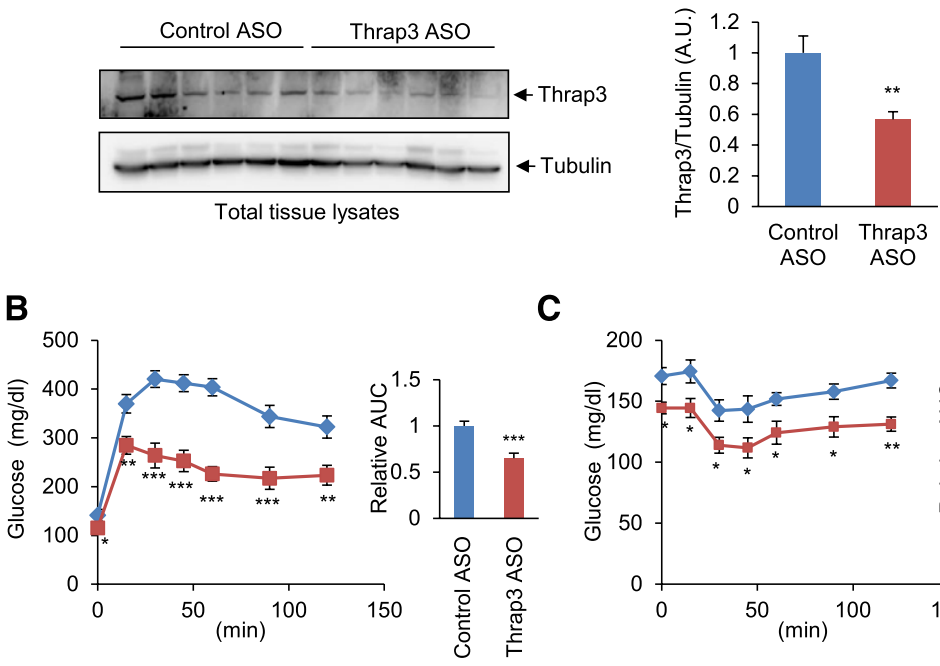

C

D

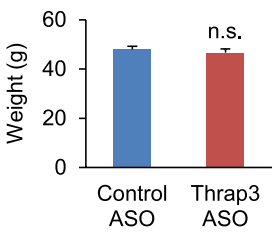

G

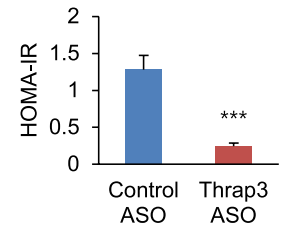

E

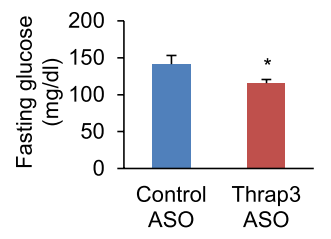

H

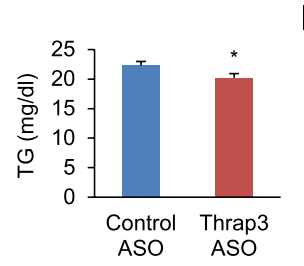

$\mathbf{F}$

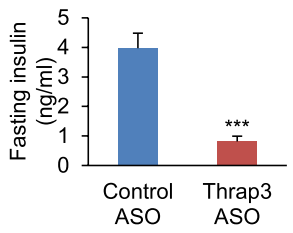

I

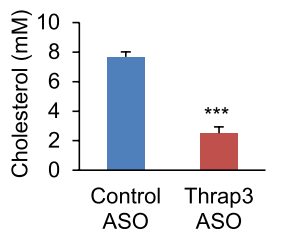

Figure 4. ASO knockdown of Thrap3 improves insulin sensitivity. (A) Control or antiThrap3 ASOs were injected in high-fat diet mice at a dose of $40 \mathrm{mg} / \mathrm{kg}$ twice a week for 3 wk. Protein levels of Thrap3 in white adipose tissues were analyzed with an anti-Thrap3 antibody. (B) Glucose tolerance tests in highfat diet mice treated with control ASOs or Thrap3 ASOs $(n=6)$. $(C)$ Insulin tolerance tests in high-fat diet mice treated with control ASOs or Thrap3 ASOs $(n=6)$. $(D-I)$ Effect of Thrap3 ASO on different metabolic parameters-body weight $(D)$, fasting glucose $(E)$, fasting insulin $(F)$, HOMA-IR $(G)$, serum triglyceride $(H)$, and serum cholesterol $(I)$ - of mice treated with control or Thrap3 ASO. Error bars are SEM. $\left(^{\star}\right) P<0.05 ;\left(^{\star \star}\right) P<0.01$; $\left({ }^{\star \star \star}\right) P<0.001$. diabetic and might also avoid the side effects and stigma that have been associated with PPAR $\gamma$ ligands (Nesto et al. 2004; Lipscombe et al. 2007).

\section{Materials and methods}

\section{Cell culture}

3T3-L1 and HEK-293 cells were obtained from American Type Culture Collection (ATCC) and were cultured in Dulbecco's modified Eagle's medium and 10\% fetal bovine serum. Adipocyte differentiation in 3T3-L1 cells was induced by treatment with $1 \mu \mathrm{M}$ dexamethasone, $0.5 \mathrm{mM}$ isobutylmethylxanthine, and 850 $\mathrm{nM}$ insulin for $48 \mathrm{~h}$. Cells were then switched to maintenance medium containing $850 \mathrm{nM}$ insulin. Lipid accumulation in the cells was detected by Oil-Red-O staining. All chemicals for cell culture were obtained from Sigma.

\section{Purification and characterization of the PPAR $\gamma$ transcriptional complex}

PPAR $\gamma$-null mouse embryonic fibroblasts (MEFs) were cultured in Dulbecco's modified Eagle's medium and 10\% fetal bovine serum. Flag-PPAR $\gamma$ wild type or Flag-PPAR $\gamma$ S273A were subcloned into a pMSCV-puro retroviral vector (Stratagene).
For retrovirus production, Phoenix packaging cells were transfected with $10 \mu \mathrm{g}$ of the retroviral vectors. After $48 \mathrm{~h}$, the viral supernatant was collected and filtered. Following infection of the cells with the retrovirus, cells expressing the ectopic virally encoded proteins were selected by incubation with $2 \mu \mathrm{g} / \mathrm{mL}$ puromycin. After treatment with vehicle or TNF- $\alpha$ for $1 \mathrm{~h}$, nuclear extracts were prepared and incubated with the immobilized anti-Flag antibodies (Flag M2 agarose; Sigma), washed in a binding buffer, and eluted by incubating with Flag peptide (Sigma). The immunoprecipitated proteins were separated by SDS-PAGE, and specific bands were excised and digested by trypsin. These were then subjected to reverse-phase LC-MS/MS using a high-resolution hybrid mass spectrometer (LTQ-Orbitrap, Thermo Scientific).

\section{DNA constructs and shRNA of Thrap3}

Various deletion mutants of Thrap3 were generated and subcloned into HA-pcDNA3.1 vector. The sequence used for the lentivial shRNA expression vector (pLKO.1, Open Biosystems) targeting Thrap3 was 5' -AATGGTCACTATGTGCTGAGC-3' . For lentiviral production, HEK-293T cells (ATCC) were transfected with 10 $\mu \mathrm{g}$ of the lentiviral vectors. Following infection of the cells with the viral vectors, cells were selected by incubation with $2 \mu \mathrm{g} / \mathrm{mL}$ puromycin. 
A

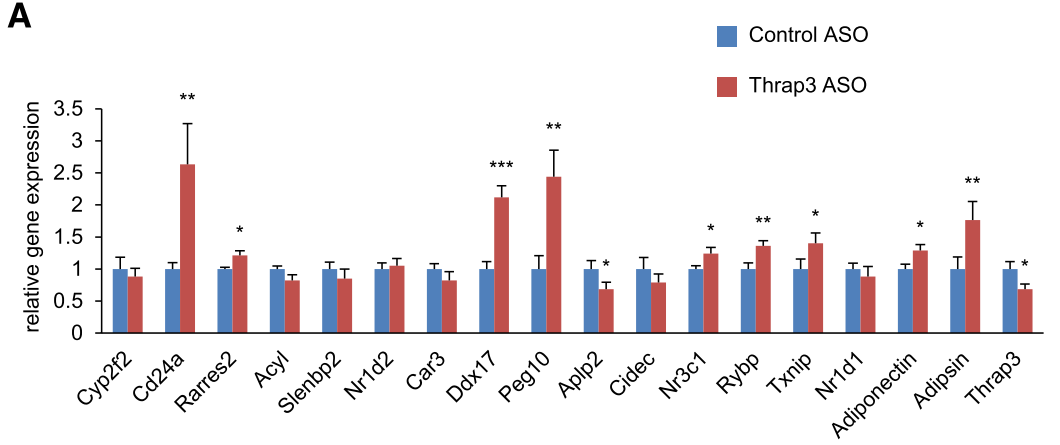

B

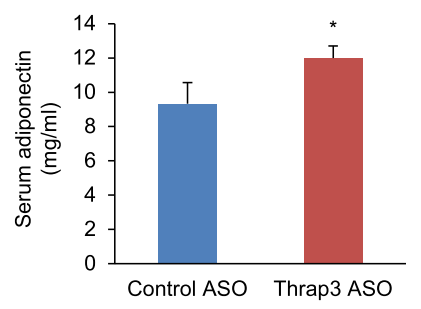

C

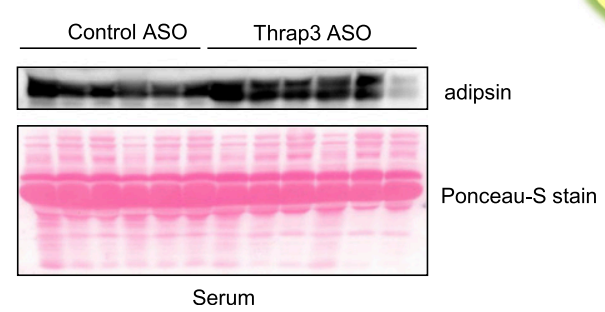

Immunoprecipitation and pull-down assay

HEK-293 cells expressing CDK5/p35, Flag-PPAR $\gamma$, or Flag-PPAR $\gamma$ S273A were collected after transient transfection. Total cell lysates were incubated with Flag M2 agarose (Sigma) at $4^{\circ} \mathrm{C}$. Immunoprecipitates or total cell lysates were analyzed with anti-Thrap3 (Santa Cruz Biotechnology), PPAR $\gamma$ (Santa Cruz Biotechnology), or a phospho-specific antibody against PO3-Ser273. Differentiated 3T3-L1 adipocytes were treated with $50 \mathrm{ng} / \mathrm{mL} \mathrm{TNF}-\alpha$ for $30 \mathrm{~min}$, and cell lysates were analyzed with the phospho-specific or PPAR $\gamma$ antibodies. For tissue lysates, white adipose tissue from mice was homogenized in RIPA buffer $(50 \mathrm{mM}$ Tris at $\mathrm{pH} 7.5,150 \mathrm{mM} \mathrm{NaCl}$, $1 \%$ NP-40, $0.5 \%$ sodium deoxycholate, $0.1 \%$ SDS with protease and phosphatase inhibitors). Biotin-conjugated peptide that contains phosphorylated Ser273 (Biotin-KTTDKpSPFVIYDC) or nonphosphopeptide (Biotin-KTTDKSPFVIYDC) was incubated with Thrap3-expressing cell lysates and analyzed with anti-Thrap3 antibody. For in vitro binding assay, fragments of the GST-fused Thrap3 (amino acids 640-680) were purified using glutathione Sepharose beads and incubated with PPAR $\gamma$-expressed cell lysates. The beads were then washed with binding buffer, and bound proteins were separated by SDS-PAGE and analyzed with antiPPAR $\gamma$ antibody.

\section{Gene expression analyses}

Total RNA was isolated from cells or tissues using Trizol reagents (Invitrogen). The RNA was reverse-transcribed using an $\mathrm{ABI}$ reverse transcription kit. Quantitative PCR reactions
Figure 5. Thrap3 is required for controlling PPAR $\gamma$ phosphorylation-mediated gene programing. (A) White adipose tissue from control or Thrap3 ASO-treated mice was examined by real-time qPCR for the expression of gene sets regulated by PPAR $\gamma$ phosphorylation. Error bars are SEM. $\left({ }^{\star}\right) P<0.05$; $\left(^{\star \star}\right) P<0.01 ;\left(^{\star \star \star}\right) P<0.001$. (B) Serums were collected from these mice, and adiponectin protein was analyzed using ELISA $(n=6) \cdot(C)$ Serums were denatured and separated by SDS-PAGE, and adipsin protein was analyzed with anti-adipsin antibody. $(D)$ Schematic model for interaction of Thrap3 with phosphorylated PPAR $\gamma$ at Ser273 and controlling diabetic gene program. were performed with SYBR Green fluorescent dye using an ABI9300 PCR machine. Relative mRNA expression was determined by the $\Delta \Delta$-Ct method normalized to tata-binding protein (TBP) levels. The sequences of primers used in this study are in Supplemental Table 1p.

\section{Animals and ASO treatment}

All animal experiments were performed according to procedures approved by Ulsan National Institute of Science and Technology's Institutional Animal Care and Use Committee. Four-week-old to 5-wk-old male C57BL/6J mice were obtained from the Jackson Laboratory. Mice were fed a regular diet (10\% kcal fat; D12450B, Research Diets, Inc.) or a high-fat diet (60\% kcal fat; D12492, Research Diets, Inc.) as indicated. ASO treatment was administered at a dosing schedule of $20 \mathrm{mg} / \mathrm{kg}$ (for regular diet mice) or $40 \mathrm{mg} / \mathrm{kg}$ (for high-fat diet mice) twice a week for $3 \mathrm{wk}$ by intraperitoneal injection. The ASO sequences used were as follows: control ASO, 5'-CCTTCCCTGAAGGTTCCTCC-3'; and Thrap3 ASO, 5'-AATGGTCACTATGTGCTGAGC-3' . ASOs were resuspended and delivered in $0.9 \%$ saline. For glucose tolerance tests, mice were fasted overnight prior to intraperitoneal injection of $2 \mathrm{~g} / \mathrm{kg}$ D-glucose. For insulin tolerance tests, mice were fasted for $4 \mathrm{~h}$ prior to intraperitoneal injection of $1 \mathrm{U} / \mathrm{kg}$ insulin. Glucose was measured in tail vein blood at intervals after injections using a Truetrack glucometer. Serum insulin (Crystal Chem), cholesterol (Cayman Chemical), TG (Cayman Chemical), and adiponectin (Millipore) were determined by ELISA. 


\section{Acknowledgments}

We are grateful for technical assistance from the In Vivo Research Center at Ulsan National Institute of Science and Technology. This work was supported by the Basic Science Research Program through the National Research Foundation of Korea (NRF) funded by Ministry of Education, Science, and Technology grant NRF-2012R1A1A1015407 (to J.H.C., S.-S.C., and E.S.K.). Y.R.Y., H.-J.J, and P.-G.S. were supported by the NRF grant funded by the Korean government (Ministry of Science, ICT [Information and Communications Technology], and Future Planning [MSIP]) (no. 2010-0028684). A.S.B. is supported by National Institutes of Health (NIH) K01DK093638, and B.M.S. is supported by NIH DK031405.

\section{References}

Berg AH, Combs TP, Du X, Brownlee M, Scherer PE. 2001. The adipocyte-secreted protein Acrp30 enhances hepatic insulin action. Nat Med 7: 947-953.

Bray GA, Bellanger T. 2006. Epidemiology, trends, and morbidities of obesity and the metabolic syndrome. Endocrine 29: 109-117.

Calle EE, Rodriguez C, Walker-Thurmond K, Thun MJ. 2003. Overweight, obesity, and mortality from cancer in a prospectively studied cohort of U.S. adults. $N$ Engl J Med 348: 1625-1638.

Chandra V, Huang P, Hamuro Y, Raghuram S, Wang Y, Burris TP, Rastinejad F. 1998. Structure of the intact PPAR- $\gamma-R X R-$ nuclear receptor complex on DNA. Nature 456: 350-356.

Chen JD, Evans RM. 1995. A transcriptional co-repressor that interacts with nuclear hormone receptors. Nature 377: 454457.

Choi JH, Banks AS, Estall JL, Kajimura S, Boström P, Laznik D, Ruas JL, Chalmers MJ, Kamenecka TM, Blüher M, et al. 2010. Anti-diabetic drugs inhibit obesity-linked phosphorylation of PPAR $\gamma$ by Cdk5. Nature 466: 451-456.

Choi JH, Banks AS, Kamenecka TM, Busby SA, Chalmers MJ, Kumar N, Kuruvilla DS, Shin Y, He Y, Bruning JB, et al. 2011. Anti-diabetic actions of a non-agonist PPAR $\gamma$ ligand blocking Cdk5-mediated phosphorylation. Nature 477: 477-481.

Cook KS, Min HY, Johnson D, Chaplinsky RJ, Flier JS, Hunt CR, Spiegelman BM. 1987. Adipsin: a circulating serine protease homolog secreted by adipose tissue and sciatic nerve. Science 237: 402-405.

DiRenzo J, Söderstrom M, Kurokawa R, Ogliastro $\mathrm{MH}$, Ricote M, Ingrey S, Hörlein A, Rosenfeld MG, Glass CK. 1997. Peroxisome proliferator-activated receptors and retinoic acid receptors differentially control the interactions of retinoid $\mathrm{X}$ receptor heterodimers with ligands, coactivators, and corepressors. Mol Cell Biol 17: 2166-2176.

Flier JS, Cook KS, Usher P, Spiegelman BM. 1987. Severely impaired adipsin expression in genetic and acquired obesity. Science 237: 405-408.

Fondell JD, Ge H, Roeder RG. 1996. Ligand induction of a transcriptionally active thyroid hormone receptor coactivator complex. Proc Natl Acad Sci 93: 8329-8333.

Fondell JD, Guermah M, Malik S, Roeder RG. 1999. Thyroid hormone receptor-associated proteins and general positive cofactors mediate thyroid hormone receptor function in the absence of the TATA box-binding protein-associated factors of TFIID. Proc Natl Acad Sci 96: 1959-1964.

Ge K, Guermah M, Yuan CX, Ito M, Wallberg AE, Spiegelman BM, Roeder RG. 2002. Transcription coactivator TRAP220 is required for PPAR $\gamma 2$-stimulated adipogenesis. Nature 417: $563-567$.
Heyd F, Lynch KW. 2010. Phosphorylation-dependent regulation of PSF by GSK3 controls CD45 alternative splicing. Mol Cell 40: $126-137$.

Hörlein AJ, Näär AM, Heinzel T, Torchia J, Gloss B, Kurokawa R, Ryan A, Kamei Y, Söderström M, Glass CK, et al. 1995. Ligand-independent repression by the thyroid hormone receptor mediated by a nuclear receptor co-repressor. Nature 377: 397-404.

Hotamisligil GS, Shargill NS, Spiegelman BM. 1993. Adipose expression of tumor necrosis factor- $\alpha$ : direct role in obesitylinked insulin resistance. Science 259: 87-91.

Hsu IR, Kim SP, Kabir M, Bergman RN. 2007. Metabolic syndrome, hyperinsulinemia, and cancer. Am I Clin Nutr 86: $867-871$.

Hu E, Liang P, Spiegelman BM. 1996. AdipoQ is a novel adiposespecific gene dysregulated in obesity. I Biol Chem 271: 10697-10703.

Ito $M$, Yuan CX, Malik S, Gu W, Fondell JD, Yamamura S, Fu ZY, Zhang X, Qin J, Roeder RG. 1999. Identity between TRAP and SMCC complexes indicates novel pathways for the function of nuclear receptors and diverse mammalian activators. Mol Cell 3: 361-370.

Ito M, Okano HJ, Darnell RB, Roeder RG. 2002. The TRAP100 component of the TRAP/Mediator complex is essential in broad transcriptional events and development. EMBO J 21: 3464-3475.

Katano-Toki A, Satoh T, Tomaru T, Yoshino S, Ishizuka T, Ishii S, Ozawa A, Shibusawa N, Tsuchiya T, Saito T, et al. 2013. THRAP3 interacts with HELZ2 and plays a novel role in adipocyte differentiation. Mol Endocrinol 27: 769-780.

Kershaw EE, Flier JS. 2004. Adipose tissue as an endocrine organ. J Clin Endocrinol Metab 89: 2548-2556.

Kim JY, van de Wall E, Laplante M, Azzara A, Trujillo ME, Hofmann SM, Schraw T, Durand JL, Li H, Li G, et al. 2007. Obesity-associated improvements in metabolic profile through expansion of adipose tissue. I Clin Invest 117: 2621-2637.

Kliewer SA, Umesono K, Mangelsdorf DJ, Evans RM. 1992. Retinoid $\mathrm{X}$ receptor interacts with nuclear receptors in retinoic acid, thyroid hormone and vitamin D3 signalling. Nature 355: 446-449.

Kumashiro N, Beddow SA, Vatner DF, Majumdar SK, Cantley JL, Guebre-Egziabher F, Fat I, Guigni B, Jurczak MJ, Birkenfeld $\mathrm{AL}$, et al. 2013. Targeting pyruvate carboxylase reduces gluconeogenesis and adiposity and improves insulin resistance. Diabetes 62: 2183-2194.

Lagathu C, Yvan-Charvet L, Bastard JP, Maachi M, QuignardBoulangé A, Capeau J, Caron M. 2006. Long-term treatment with interleukin- $1 \beta$ induces insulin resistance in murine and human adipocytes. Diabetologia 49: 2162-2173.

Lande-Diner L, Boyault C, Kim JY, Weitz CJ. 2013. A positive feedback loop links circadian clock factor CLOCK-BMAL1 to the basic transcriptional machinery. Proc Natl Acad Sci 110: $16021-16026$

Lehmann JM, Moore LB, Smith-Oliver TA, Wilkison WO, Willson TM, Kliewer SA. 1995. An antidiabetic thiazolidinedione is a high affinity ligand for peroxisome proliferator-activated receptor $\gamma$ (PPAR $\gamma)$. I Biol Chem 270: 12953-12956.

Li P, Fan W, Xu J, Lu M, Yamamoto H, Auwerx J, Sears DD, Talukdar S, Oh D, Chen A, et al. 2011. Adipocyte NCoR knockout decreases PPAR $\gamma$ phosphorylation and enhances PPAR $\gamma$ activity and insulin sensitivity. Cell 147: 815-826.

Lipscombe LL, Gomes T, Lévesque LE, Hux JE, Juurlink DN, Alter DA. 2007. Thiazolidinediones and cardiovascular outcomes in older patients with diabetes. JAMA 298: 26342643. 
Lo JC, Ljubicic S, Leibiger B, Kern M, Leibiger IB, Moede T, Kelly ME, Chatterjee Bhowmick D, Murano I, Cohen P, et al. 2014. Adipsin is an adipokine that improves $\beta$ cell function in diabetes. Cell 158: 41-53.

Maeda N, Shimomura I, Kishida K, Nishizawa H, Matsuda M, Nagaretani H, Furuyama N, Kondo H, Takahashi M, Arita Y, et al. 2002. Diet-induced insulin resistance in mice lacking adiponectin/ACRP30. Nat Med 8: 731-737.

Mangelsdorf DJ, Evans RM. 1995. The RXR heterodimers and orphan receptors. Cell 83: 841-850.

Mokdad AH, Ford ES, Bowman BA, Dietz WH, Vinicor F, Bales VS, Marks JS. 2001. Prevalence of obesity, diabetes, and obesity-related health risk factors. JAMA 289: 76-79.

Nesto RW, Bell D, Bonow RO, Fonseca V, Grundy SM, Horton ES, Le Winter M, Porte D, Semenkovich CF, Smith S, et al. 2004. Thiazolidinedione use, fluid retention, and congestive heart failure: a consensus statement from the American Heart Association and American Diabetes Association. Diabetes Care 27: 256-263.

Nolte RT, Wisely GB, Westin S, Cobb JE, Lambert MH, Kurokawa R, Rosenfeld MG, Willson TM, Glass CK, Milburn MV. 1998. Ligand binding and co-activator assembly of the peroxisome proliferator-activated receptor- $\gamma$. Nature 395: 137-143.

Puigserver P, Wu Z, Park CW, Graves R, Wright M, Spiegelman BM. 1998. A cold-inducible coactivator of nuclear receptors linked to adaptive thermogenesis. Cell 92: 829-839.

Rosen ED, Spiegelman BM. 2014. What we talk about when we talk about fat. Cell 156: 20-44.

Rosen BS, Cook KS, Yaglom J, Groves DL, Volanakis JE, Damm D, White T, Spiegelman BM. 1989. Adipsin and complement factor D activity: an immune-related defect in obesity. Science 244: 1483-1487.

Tontonoz P, Spiegelman BM. 2008. Fat and beyond: the diverse biology of PPAR $\gamma$. Annu Rev Biochem 77: 289-312.

Tontonoz P, Hu E, Spiegelman BM. 1994. Stimulation of adipogenesis in fibroblasts by PPAR $\gamma 2$, a lipid-activated transcription factor. Cell 79: 1147-1156.

Trujillo ME, Scherer PE. 2006. Adipose tissue-derived factors: impact on health and disease. Endocr Rev 27: 762-778.

Unger RH. 2002. Lipotoxic diseases. Annu Rev Med 53: 319336.

Van Gaal LF, Mertens IL, De Block CE. 2006. Mechanisms linking obesity with cardiovascular disease. Nature 444: 875-880.

Watts LM, Manchem VP, Leedom TA, Rivard AL, McKay RA, Bao D, Neroladakis T, Monia BP, Bodenmiller DM, Cao JX, et al. 2005. Reduction of hepatic and adipose tissue glucocorticoid receptor expression with antisense oligonucleotides improves hyperglycemia and hyperlipidemia in diabetic rodents without causing systemic glucocorticoid antagonism. Diabetes 54: 1846-1853.

Willson TM, Lambert MH, Kliewer SA. 2001. Peroxisome proliferator-activated receptor $\gamma$ and metabolic disease. Annu Rev Biochem 70: 341-367.

Yamauchi T, Kamon J, Waki H, Terauchi Y, Kubota N, Hara K, Mori Y, Ide T, Murakami K, Tsuboyama-Kasaoka N, et al. 2001. The fat-derived hormone adiponectin reverses insulin resistance associated with both lipoatrophy and obesity. Nat Med 7: 941-946.

Yuan CX, Ito M, Fondell JD, Fu ZY, Roeder RG. 1998. The TRAP220 component of a thyroid hormone receptor-associated protein (TRAP) coactivator complex interacts directly with nuclear receptors in a ligand-dependent fashion. Proc Natl Acad Sci 95: 7939-7944. 


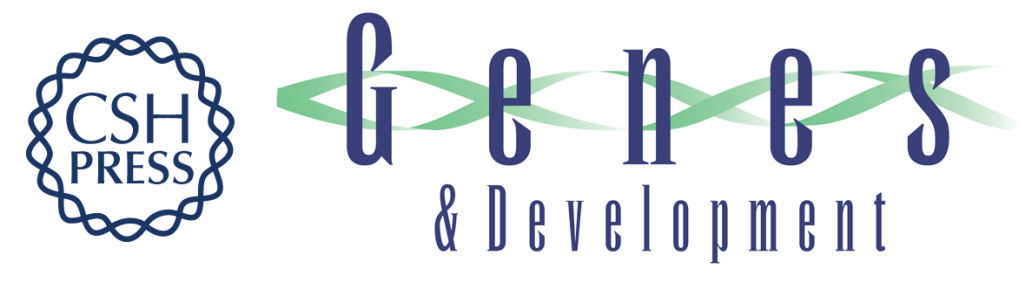

\section{Thrap3 docks on phosphoserine 273 of PPAR $\gamma$ and controls diabetic gene programming}

Jang Hyun Choi, Sun-Sil Choi, Eun Sun Kim, et al.

Genes Dev. 2014, 28: originally published online October 14, 2014

Access the most recent version at doi:10.1101/gad.249367.114

\section{Supplemental http://genesdev.cshlp.org/content/suppl/2014/10/10/gad.249367.114.DC1 Material}

References This article cites 48 articles, 15 of which can be accessed free at: http://genesdev.cshlp.org/content/28/21/2361.full.html\#ref-list-1

Creative This article is distributed exclusively by Cold Spring Harbor Laboratory Press for the first Commons six months after the full-issue publication date (see

License http://genesdev.cshlp.org/site/misc/terms.xhtml). After six months, it is available under a Creative Commons License (Attribution-NonCommercial 4.0 International), as described at http://creativecommons.org/licenses/by-nc/4.0/.

Email Alerting Receive free email alerts when new articles cite this article - sign up in the box at the top Service right corner of the article or click here.

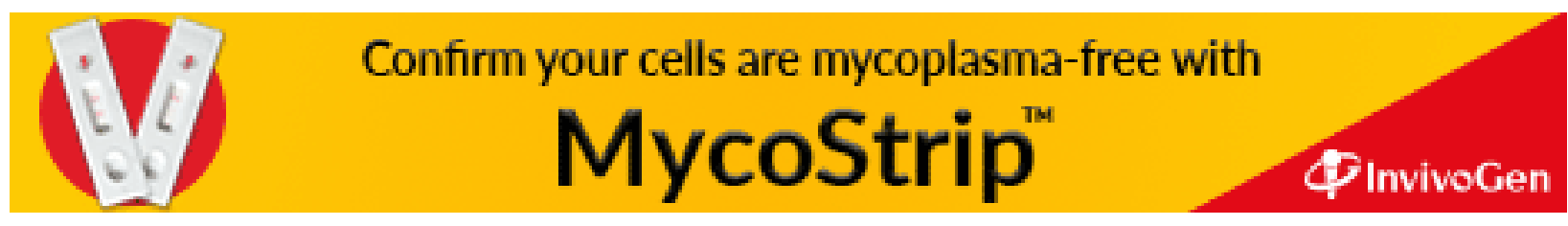

